\title{
Evolutionary ecology of the visual opsin gene sequence and its expression in turbot (Scophthalmus maximus)
}

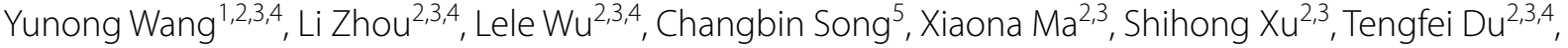
Xian $\mathrm{Li}^{1,2,3^{*}} \mathrm{~B}$ and Jun $\mathrm{Li}^{2,3,4}$

\begin{abstract}
Background: As flatfish, turbot undergo metamorphosis as part of their life cycle. In the larval stage, turbot live at the ocean surface, but after metamorphosis they move to deeper water and turn to benthic life. Thus, the light environment differs greatly between life stages. The visual system plays a great role in organic evolution, but reports of the relationship between the visual system and benthic life are rare. In this study, we reported the molecular and evolutionary analysis of opsin genes in turbot, and the heterochronic shifts in opsin expression during development.

Results: Our gene synteny analysis showed that subtype $\mathrm{RH} 2 \mathrm{C}$ was not on the same gene cluster as the other four green-sensitive opsin genes $(\mathrm{RH} 2)$ in turbot. It was translocated to chromosome 8 from chromosome 6 . Based on branch-site test and spectral tuning sites analyses, E122Q and M207L substitutions in RH2C, which were found to be under positive selection, are closely related to the blue shift of optimum light sensitivities. And real-time PCR results indicated the dominant opsin gene shifted from red-sensitive (LWS) to RH2B1 during turbot development, which may lead to spectral sensitivity shifts to shorter wavelengths.

Conclusions: This is the first report that $R H 2 C$ may be an important subtype of green opsin gene that was retained by turbot and possibly other flatfish species during evolution. Moreover, E122Q and M207L substitutions in RH2C may contribute to the survival of turbot in the bluish colored ocean. And heterochronic shifts in opsin expression may be an important strategy for turbot to adapt to benthic life.
\end{abstract}

Keywords: Turbot, Benthic life, Adaption, Opsin, Heterochronic shift

\section{Background}

To survive, all organisms must react to changes in the physical environment, such as temperature, circadian rhythm of light, and humidity [1]. Thus, to frame the evolutionary perspective about the molecular basis of organismal adaptation and biology, sensory systems are generally selected as ideal models [2]. Vision is closely related to behaviors such as foraging, mating, parental

\footnotetext{
*Correspondence: lixian@ouc.edu.cn

${ }^{1}$ College of Fisheries, Ocean University of China, Qingdao 266003,

People's Republic of China

Full list of author information is available at the end of the article
}

care, and avoiding predation. As it allows for almost instantaneous transmission of information, vision likely plays a great role in diversification [3]. Vision formation involves retinal reception, integration, and higher-order brain processing $[4,5]$. Retinal reception is mediated by visual pigments, which consist of one opsin protein, a group of G protein-coupled receptors, and one chromophore (11-cis-retinal, A1, or 11-cis-3, 4-dehydroretinal, A2) [3].

Due to water absorption and scattering of light, the photic environment of the aquatic system in which fish live changes rapidly with depth, especially a shift to 
predominantly blue wavelengths in the ocean at about 60-75 depth $[1,2]$. Teleost code five classes of visual opsin genes: (1) RH1 (rhodopsin, spectral peak absorbances around $500 \mathrm{~nm}$ ) for dim light; (2) RH2 (rhodopsin-like opsin, 470-510 nm) for green; (3) SWS1 (short wavelength-sensitive type 1, 360-430 nm) for ultraviolet; (4) SWS2 (SWS1-like opsin, 440-460 nm) for blue; and (5) LWS (long wavelength-sensitive, $510-560 \mathrm{~nm}$ ) for red. With the exception of $R H 1$, which is expressed in rod photoreceptors, the other four classes are expressed in cone photoreceptors [3]. The cone opsin genes derived from two rounds of whole genome duplication [6]. It is believed that after several additional duplication events, diverse opsin repertoires were maintained among different species [7-12]. RH2 and LWS duplication events were most prevalent in ray-finned fish, and tandem duplication seems to have produced more duplicates [13]. Due to substitution in key sites, the multiple opsin subtypes from duplication generally have different spectral peak absorbances $\left(\lambda_{\max }\right)$, which helps enrich the visual system $[2,3,7,10]$.

In addition to the adaptive evolution of gene sequences, heterochronic shifts in visual opsin expression are an important mechanism of spectral tuning [14, 15]. For example, single cones in rainbow trout (Oncorhynchus mykiss) switch opsin expression from SWS1 to SWS2 during the juvenile period [16], and in winter flounder (Pleuronectes americanus), only $\mathrm{RH} 2$ is expressed in the pre-metamorphic retina, whereas RH1, SWS2, and $L W S$ are also expressed in the post-metamorphic retina [17]. Besides ontogenetic changes, plasticity of visual opsin expression in response to different photic environments is an important strategy that allows rapid adaptation to environmental changes. Plastic opsin expression was reported to have a profound effect on Nile tilapia (Oreochromis niloticus) and guppy (Poecilia reticulate) during development. Specifically, juveniles and adults O. niloticus differ in spectral reflectance after the two environmental light treatments, demonstrating that environmental light plays a great role in signal production throughout ontogeny. And developmental plasticity in vision may help $P$. reticulate overcome increased turbidity $[18,19]$. It was also reported for the adult stage of fish such as red shiner (Cyprinella lutrensis) and bluefin killifish (Lucania goodei) [20, 21]. Additionally, a recent study showed that opsin coexpression might be a novel mechanism for modulating color vision [22]. However, it is unclear whether the direction and extent of opsin expression plasticity is limited by ontogeny [23].

The turbot (Scophthalmus maximus) is an important aquaculture species with great commercial value. As a flatfish, metamorphosis is a critical part of its life cycle $[24,25]$. During early life stage, S. maximus larvae live at the ocean surface and undergo metamorphosis characterized by asymmetrical body transformation coupled with eye migration. After metamorphosis, turbot move to deep water and enter a benthic phase [26, 27]. This change in habitat results in a great shift in environmental conditions, and its visual system may change accordingly. For example, the photoreceptors in the retina are mainly composed of cone cells before metamorphosis, while during metamorphosis the rod cells increase and become the main component of photoreceptors in premetamorphic phase [28, 29]. However, visual characteristics and the opsin expression pattern of turbot and their relationship to benthic life remain unknown. In the present study, we investigated the selective pressure acting on turbot and eight other teleost species and conducted spectral tuning site and synteny analyses to evaluate the adaptive evolution of turbot visual opsin genes. We also investigated the heterochronic shifts during development of turbot. Results of this study enrich the understanding of sensory adaption in demersal fish.

\section{Results}

\section{Phylogeny and syntenic analysis of turbot visual opsin}

We obtained an unrooted visual opsin phylogenetic tree of turbot and eight other species constructed using the maximum-likelihood method (Fig. 1). The tree confirmed the identities of turbot opsin genes: RH1, SWS1, SWS2, RH2A1, RH2A2, RH2B1, RH2B2, RH2C, and LWS. Unlike other single-copy opsin genes, turbot have five

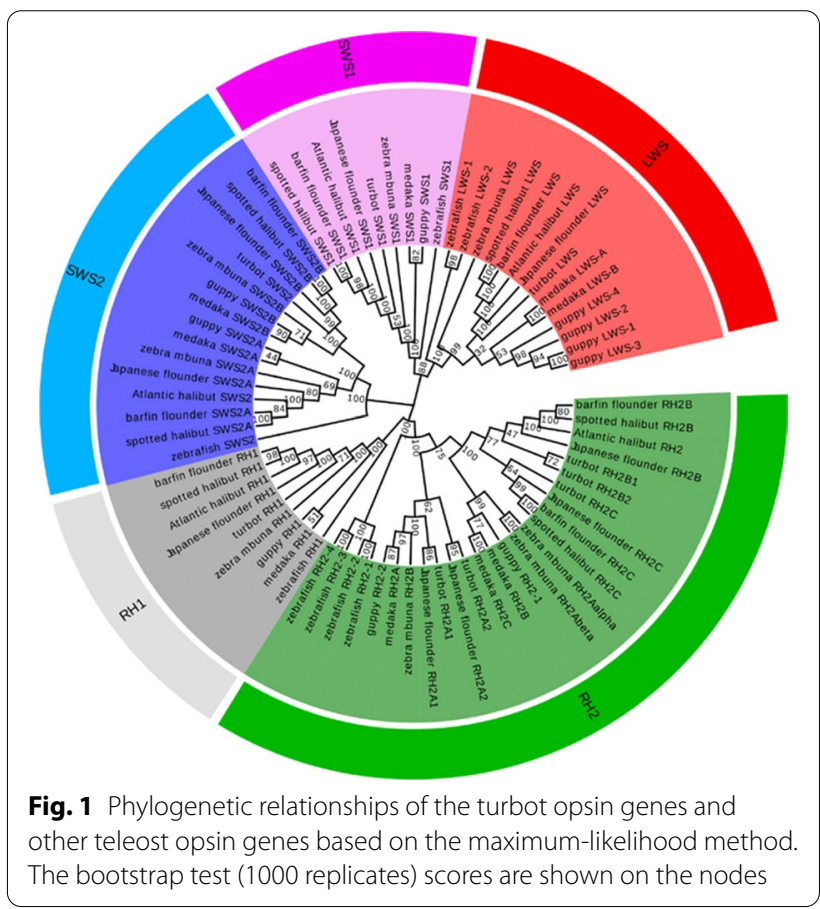


RH2 paralogs. Figure 2 shows the results of comparative synteny analyses among six selected teleost species. In general, opsin gene positions were conserved among teleosts. For example, the $R H 1$ gene was typically positioned between the gene loci of prickle $2 a$ and ren. In addition to $R H 2 C$, four other $R H 2$ genes of turbot were located in tandem on chromosome 6 . By comparing the syntenic region containing $\mathrm{RH} 2 \mathrm{C}$, we found that although the genomic regions both downstream and upstream were otherwise maintained, $R H 2 C$ was missing in the other five species (Fig. 2b). When we extended the analysis to all fish genomes that could be analyzed, the $R H 2 C$ locus was still not found. Similarly, LWS-1, LWS-2, and LWS3 of guppy formed a tandem gene cluster, while LWS-4 was located on chromosome LG21 (Fig. 2c). Additionally, SWS1 was not present in the tongue sole genome (Fig. 2a).

\section{Natural selection and spectral tuning sites analysis}

To evaluate the selective constraints acting at the branch level in teleosts, branch-specific selection analysis was performed. In all cases of opsin genes, the free-ratio model provided a better fit, indicating the heterogeneity of $\omega$ values (nonsynonymous/synonymous rate ratio, $\omega=d N / d S$ ) among branches (Table 1). For the branchsite models, the test was conducted on a particular branch of the tree. The LRT comparisons between model $A$ and the null model revealed several sites under positive selection on nine branches of the tree (red labeled branches in Fig. S1). These sites under episodes of positive selection are listed in Table 2. Among the lineages selected in the phylogenetic tree, only LWS lacked a positive selection site. Furthermore, positive results were found for all branches of zebrafish except LWS. Among all selected branches, the SWS2 branch of zebrafish had the most sites.

Based on amino acid multiple alignments, we surveyed the main tuning sites involved in spectral sensitivity. Tables 3, 4 show the results for $\mathrm{RH} 2$ and $\mathrm{RH} 1$, respectively, and the others are shown in Additional file 1: Tables $\mathrm{S} 2-4$. Asparagine $(\mathrm{N})$ was present at site 83 in five flatfish species, while the other teleost genomes had aspartic acid (D) in RH1; the other three sites have yet to be defined. With the exception of Atlantic halibut, the other four flounders all had changes of glutamic acid (E) to glutamine $(\mathrm{Q})$ at site 122 and methionine $(\mathrm{M})$ to

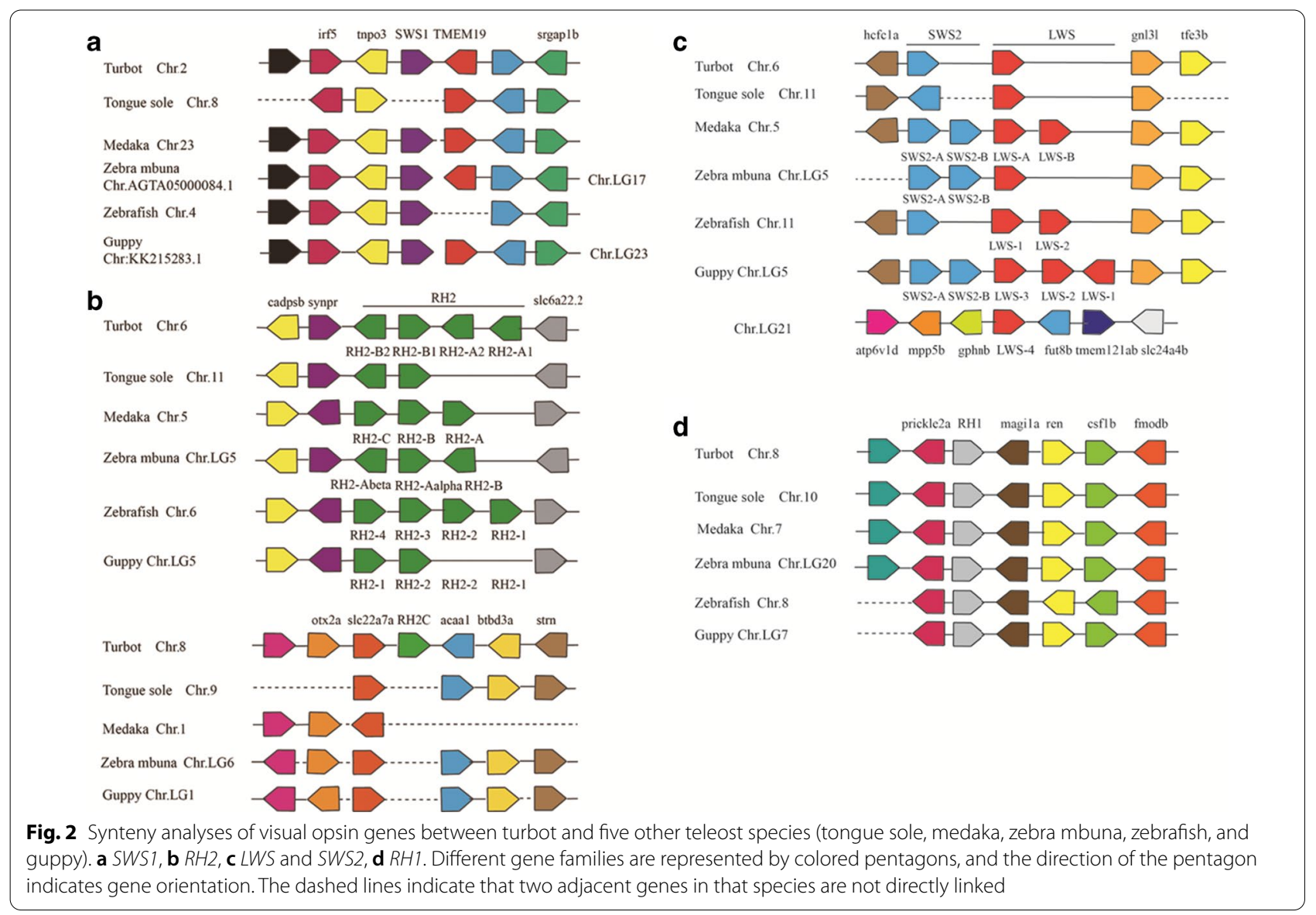


Table 1 Statistics of branch-specific model analysis of turbot and other teleost species

\begin{tabular}{lcccc}
\hline Gene & $\operatorname{lnL}(\mathbf{1} \boldsymbol{\omega}$ model) & $\operatorname{lnL}$ (free $\boldsymbol{\omega}$ model) & Likelihood ratio test & $P$ Values \\
\hline LWS & -4964.165032 & -4922.267355 & 83.795354 & $<0.001$ \\
SWS1 & -4253.724995 & -4240.774669 & 25.900652 & 0.0391 \\
SWS2 & -8001.473925 & -7970.454002 & 62.039846 & $<0.001$ \\
RH2 & $-10,370.70927$ & $-10,296.73427$ & 147.949996 & $<0.001$ \\
RH1 & -3734.012013 & -3705.674753 & 56.67452 & $<0.001$ \\
\hline
\end{tabular}

The likelihood ratio test is to determine whether the free $\omega$ model fits the data significantly better than the one $\omega$ model. The $\omega$ for each branch are not shown. In $L$ In likelihood

Table 2 Parameter estimates of branch-site models and predicted positively selected sites

\begin{tabular}{|c|c|c|c|c|c|c|}
\hline \multirow[t]{2}{*}{ Opsin } & \multirow[t]{2}{*}{ Clade } & \multicolumn{2}{|l|}{$\ln L$} & \multirow[t]{2}{*}{ LRT } & \multirow[t]{2}{*}{$P$} & \multirow[t]{2}{*}{ Positively selected sites } \\
\hline & & Null & modelA & & & \\
\hline \multirow[t]{7}{*}{$\mathrm{RH} 2$} & a & $-10,169.10$ & $-10,169.10$ & 0 & 1 & - \\
\hline & $\mathrm{b}$ & $-10,166.54$ & $-10,164.23$ & 4.62 & 0.0315 & $\begin{array}{l}19(0.881) 31(0.628) 95(0.945) 109(0.882) 122(0.511) 169(0.501) 207(0.966) 266 \\
\quad(0.604) 273(0.949) 320(0.578)\end{array}$ \\
\hline & c & $-10,169.10$ & $-10,169.10$ & 0 & 1 & - \\
\hline & $d$ & $-10,167.62$ & $-10,165.03$ & 5.16 & 0.0230 & $105(0.612) 217(0.993)$ \\
\hline & e & $-10,168.60$ & $-10,168.58$ & 0.03 & 0.8636 & - \\
\hline & f & $-10,166.92$ & $-10,162.26$ & 9.32 & 0.0022 & $49(0.944) 95$ (0.733) 270 (0.982) 307 (0.907) \\
\hline & g & $-10,148.85$ & $-10,136.84$ & 24.01 & $<0.001$ & $\begin{array}{l}14(0.875) 33(0.514) 50(0.946) 65(0.770) 84(0.948) 151(0.523) 195(0.951) 197 \\
(0.845) 198(0.600) 217(0.945) 239(0.528) 254(0.952) 286(0.502) 290(0.594) 297 \\
(0.581) 321(0.757) 322(0.966) 323(0.990) 325(0.979) 328(0.649) 329(0.770) 330 \\
(0.772)\end{array}$ \\
\hline \multirow[t]{4}{*}{$\mathrm{RH} 1$} & a & -3629.453904 & -3625.696675 & 57.51 & 0.0061 & 35 (0.769) $126(0.674) 196$ (0.858) 210 (0.879) 235 (0.911) 236 (0.959) 281 (0.773) \\
\hline & $b$ & -3632.72 & -3632.72 & 0 & 1 & - \\
\hline & $c$ & -3632.72 & -3632.72 & 0 & 1 & - \\
\hline & $d$ & -3630.82 & -3630.82 & $4 \mathrm{E}-06$ & 1 & - \\
\hline \multirow[t]{6}{*}{ SWS2 } & a & -7840.16 & -7831.84 & 16.63 & $<0.001$ & $\begin{array}{l}2(0.572) 5(0.605) 10(0.815) 14(0.801) 15(0.575) 21(0.841) 22(0.579) 25(0.507) 27 \\
(0.805) 42(0.552) 44(0.889) 45(0.598) 51(0.605) 55(0.623) 87(0.570) 88(0.617) \\
91(0.567) 95(0.613) 99(0.510) 123(0.556) 125(0.539) 156(0.601) 162(0.619) 166 \\
(0.598) 244(0.600) 257(0.600) 269(0.670) 279(0.604) 283(0.853) 301(0.685) 315 \\
(0.708) 328(0.858) 329(0.818) 332(0.577) 335(0.596) 339(0.533) 341(0.545) 346 \\
(0.659) 349(0.687)\end{array}$ \\
\hline & $b$ & -7851.02 & -7848.07 & 5.88 & 0.0152 & $38(0.560) 99(0.904) 276(0.687) 299$ (0.983) \\
\hline & c & -7852.17 & -7850.19 & 3.97 & 0.0463 & $18(0.894)$ \\
\hline & $d$ & -7852.21 & -7852.21 & 0 & 1 & - \\
\hline & e & -7852.13 & -7852.10 & 0.06 & 0.8135 & - \\
\hline & f & -7852.21 & -7851.96 & 0.50 & 0.4798 & - \\
\hline \multirow[t]{3}{*}{ SWS1 } & a & -4194.06 & -4194.06 & 0 & 1 & - \\
\hline & $\mathrm{b}$ & -4194.59 & -4193.82 & 1.54 & 0.2146 & - \\
\hline & c & -4189.36 & -4185.92 & 6.87 & 0.0087 & $\begin{array}{l}8(0.895) 9(0.860) 10(0.788) 11(0.765) 16(0.704) 27(0.895) 56(0.678) 70(0.888) 125 \\
\quad(0.746) 145(0.751) 185(0.881) 194(0.766) 263(0.792) 342(0.512)\end{array}$ \\
\hline \multirow[t]{4}{*}{ LWS } & a & -4828.06 & -4828.06 & 0 & 1 & - \\
\hline & $\mathrm{b}$ & -4828.06 & -4828.06 & 0 & 1 & - \\
\hline & c & -4828.06 & -4828.06 & 0 & 1 & - \\
\hline & $d$ & -4828.06 & -4828.06 & 0 & 1 & - \\
\hline
\end{tabular}

InL In likelihood, LRT likelihood ratio test, - no positively selected sites

leucine (L) at site 207 in RH2C. For SWS1, sites 46 and 114 of turbot contained phenylalanine (F) and alanine (A), respectively, but serine (S) was present in those locations for the other four flatfish species. Moreover, in the $\mathrm{b}$ branch of SWS2 in the tree (Additional file 1: Fig. S1), all four species had the same amino acid substitution 
Table 3 Comparison of representative spectral tuning sites among teleost $\mathrm{RH} 2$ opsins

\begin{tabular}{|c|c|c|c|c|}
\hline Tuning site & 97 & 122 & 207 & 292 \\
\hline \multicolumn{5}{|c|}{ Spotted halibut } \\
\hline $\mathrm{RH} 2 \mathrm{~B}$ & $\mathrm{~S}$ & $E$ & M & A \\
\hline $\mathrm{RH} 2 \mathrm{C}$ & $\mathrm{T}$ & Q & $L$ & A \\
\hline \multicolumn{5}{|c|}{ Barfin flounder } \\
\hline $\mathrm{RH} 2 \mathrm{~B}$ & $S$ & $E$ & M & A \\
\hline $\mathrm{RH} 2 \mathrm{C}$ & $\mathrm{T}$ & Q & L & A \\
\hline \multicolumn{5}{|c|}{ Atlantic Halibut } \\
\hline $\mathrm{RH} 2$ & $\mathrm{~S}$ & $E$ & M & A \\
\hline \multicolumn{5}{|c|}{ Japanese flounder } \\
\hline $\mathrm{RH} 2 \mathrm{~A} 1$ & $\mathrm{~S}$ & Q & M & A \\
\hline $\mathrm{RH} 2 \mathrm{~A} 2$ & $\mathrm{~T}$ & Q & M & $A$ \\
\hline $\mathrm{RH} 2 \mathrm{~B}$ & $\mathrm{~S}$ & $E$ & M & A \\
\hline $\mathrm{RH} 2 \mathrm{C}$ & $S$ & $Q$ & $L$ & A \\
\hline \multicolumn{5}{|l|}{ Turbot } \\
\hline $\mathrm{RH} 2 \mathrm{~A} 1$ & $\mathrm{~S}$ & Q & $L$ & A \\
\hline $\mathrm{RH} 2 \mathrm{~A} 2$ & $\mathrm{~T}$ & Q & M & A \\
\hline $\mathrm{RH} 2 \mathrm{~B} 1$ & $\mathrm{~S}$ & $E$ & M & A \\
\hline $\mathrm{RH} 2 \mathrm{~B} 2$ & $\mathrm{~S}$ & $E$ & M & A \\
\hline $\mathrm{RH} 2 \mathrm{C}$ & $\mathrm{S}$ & Q & L & A \\
\hline \multicolumn{5}{|l|}{ Cichlids } \\
\hline $\mathrm{RH} 2 \mathrm{Aa}$ & $\mathrm{S}$ & $E$ & M & A \\
\hline $\mathrm{RH} 2 \mathrm{~A} \beta$ & $\mathrm{S}$ & $E$ & M & A \\
\hline $\mathrm{RH} 2 \mathrm{~B}$ & $\mathrm{~S}$ & Q & M & A \\
\hline \multicolumn{5}{|l|}{ Medaka } \\
\hline $\mathrm{RH} 2 \mathrm{~A}$ & $\mathrm{~S}$ & Q & M & S \\
\hline $\mathrm{RH} 2 \mathrm{~B}$ & $\mathrm{~S}$ & $E$ & M & A \\
\hline $\mathrm{RH} 2 \mathrm{C}$ & $\mathrm{S}$ & Q & M & A \\
\hline \multicolumn{5}{|l|}{ Guppy } \\
\hline $\mathrm{RH} 2-1$ & $\mathrm{~S}$ & $E$ & M & A \\
\hline $\mathrm{RH} 2-2$ & $\mathrm{~S}$ & Q & $L$ & A \\
\hline \multicolumn{5}{|l|}{ Zebrafish } \\
\hline $\mathrm{RH} 2-1$ & $C$ & Q & M & A \\
\hline $\mathrm{RH} 2-2$ & C & Q & M & A \\
\hline $\mathrm{RH} 2-3$ & $\mathrm{~T}$ & Q & M & A \\
\hline $\mathrm{RH} 2-4$ & $\mathrm{~T}$ & $E$ & M & $A$ \\
\hline
\end{tabular}

Marked in Italics are two positively selected sites of $\mathrm{RH} 2 \mathrm{C}$

of valine $(\mathrm{V})$ for threonine $(\mathrm{T})$ at site 99 . We also found a turbot-specific amino acid site (122S) in SWS2.

\section{Divergence time of turbot $\mathrm{RH} 2$ genes}

The time that the turbot $\mathrm{RH} 2$ genes diverged was estimated by MCMCTree using the soft fossil constraints method, and then we obtained an evolutionary pathway (Fig. 3). We speculated that five $R H 2$ genes were the product of several duplication events. The proposed first divergence time was 166 (139-193) million years ago (Mya) in the Jurassic, which formed $R H 2 A$
Table 4 Comparison of representative spectral tuning sites among teleost $\mathrm{RH} 1$ opsins

\begin{tabular}{lllll}
\hline Tuning site & $\mathbf{8 3}$ & $\mathbf{1 2 2}$ & $\mathbf{2 6 1}$ & $\mathbf{2 9 2}$ \\
\hline Spotted halibut & N & E & F & A \\
Barfin flounder & N & E & F & A \\
Atlantic Halibut & N & E & F & A \\
Japanese flounder & N & E & F & A \\
Turbot & N & E & F & A \\
Medaka & D & E & F & A \\
Guppy & D & E & F & A \\
Cichlids & D & E & F & A \\
Zebrafish & D & E & F & A \\
\hline
\end{tabular}

and $R H 2 B / R H 2 C$. The third divergence (about $71 \mathrm{Mya}$ ) created $R H 2 B$ and $R H 2 C$. The divergence times of $R H 2 A 1 / R H 2 A 2$ and $R H 2 B 1 / R H 2 B 2$ were estimated to be 87 (51-128) and 34 (15-55) Mya, respectively. The divergence of $R H 2 B 1 / R H 2 B 2$ was the latest one, and it occurred in the Tertiary.

\section{Ontogenetic shift of opsin gene expression in turbot}

In these experiments, expression levels of visual opsin genes in turbot at different developmental stages were determined by qPCR. Eight of the visual opsin genes were expressed at a low level at 0.5 and 18 months of age, but RH1 was highly expressed at 18 months of age. From 1 to 9 months of age, RH1, SWS2, and SWS1 expression significantly increased and $L W S, R H 2 A 1, R H 2 B 2$, and $R H 2 C$ expression significantly decreased as turbot grew. No significant change was detected in $R H 2 A 2$ and $R H 2 B 1$ gene expression throughout ontogeny from 1 to 9 months age (Fig. 4). From 4 to 18 months of age, RH1 expression maintained consistently at a high-level. The expression levels of SWS1 and SWS2 at 9 months of age could be twice as much as that at 1 month of age. However, the expression levels of them at 18 months of age are both very low. In the case of $L W S$, its expression level gradually decreased during the development of 4-18 months of age. Among the RH2 genes, RH2A1/RH2B2 and $R H 2 A 2 / R H 2 B 1$ exhibited the same expression pattern throughout ontogeny, and the pattern for $R H 2 C$ was close to that of $R H 2 A 2$ and $R H 2 B 1$. When we analyzed the proportional opsin gene expression of each cone opsin gene, we found that $L W S, R H 2 B 1$, and $R H 2 C$ were the three genes present in the highest proportions. The maximum LWS expression level was 53.9\% at 1 month of age, while that of $R H 2 B 1$ was $63.3 \%$ at 9 months of age. Thus, the dominant opsin shifted from LWS to RH2B1 during turbot development (Table 5). 


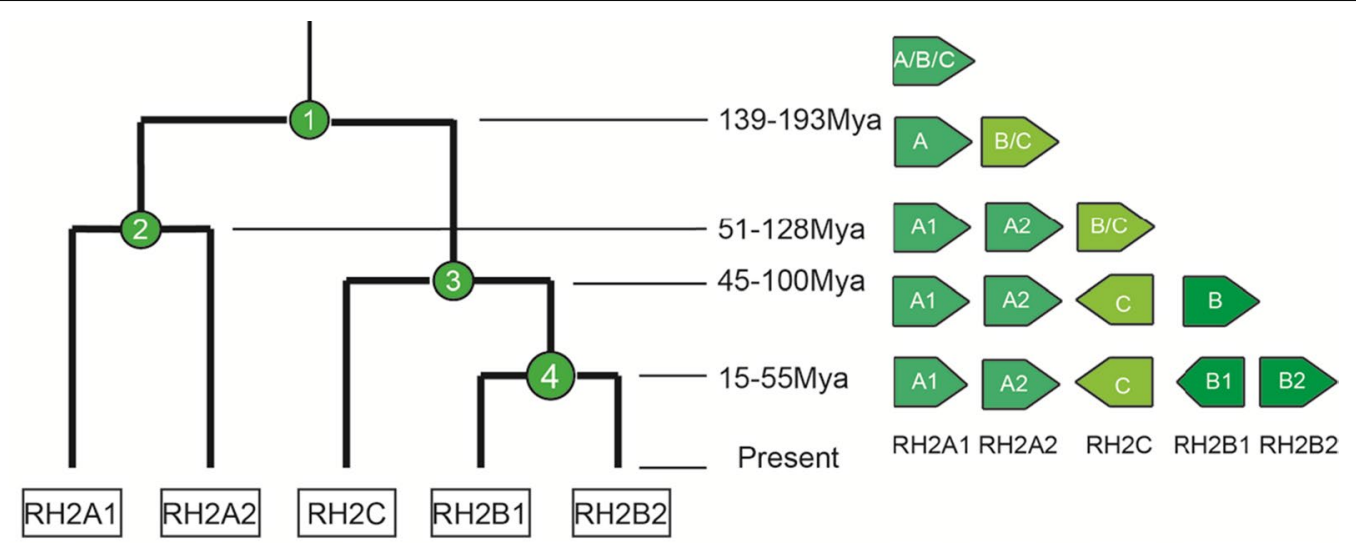

Fig. 3 An inferred evolutionary pathway of turbot $\mathrm{RH} 2$ genes. The number on each node of the dendrogram (left) represents a duplication event, whereas the right side shows the changes in $\mathrm{RH} 2$ gene orientations during evolution

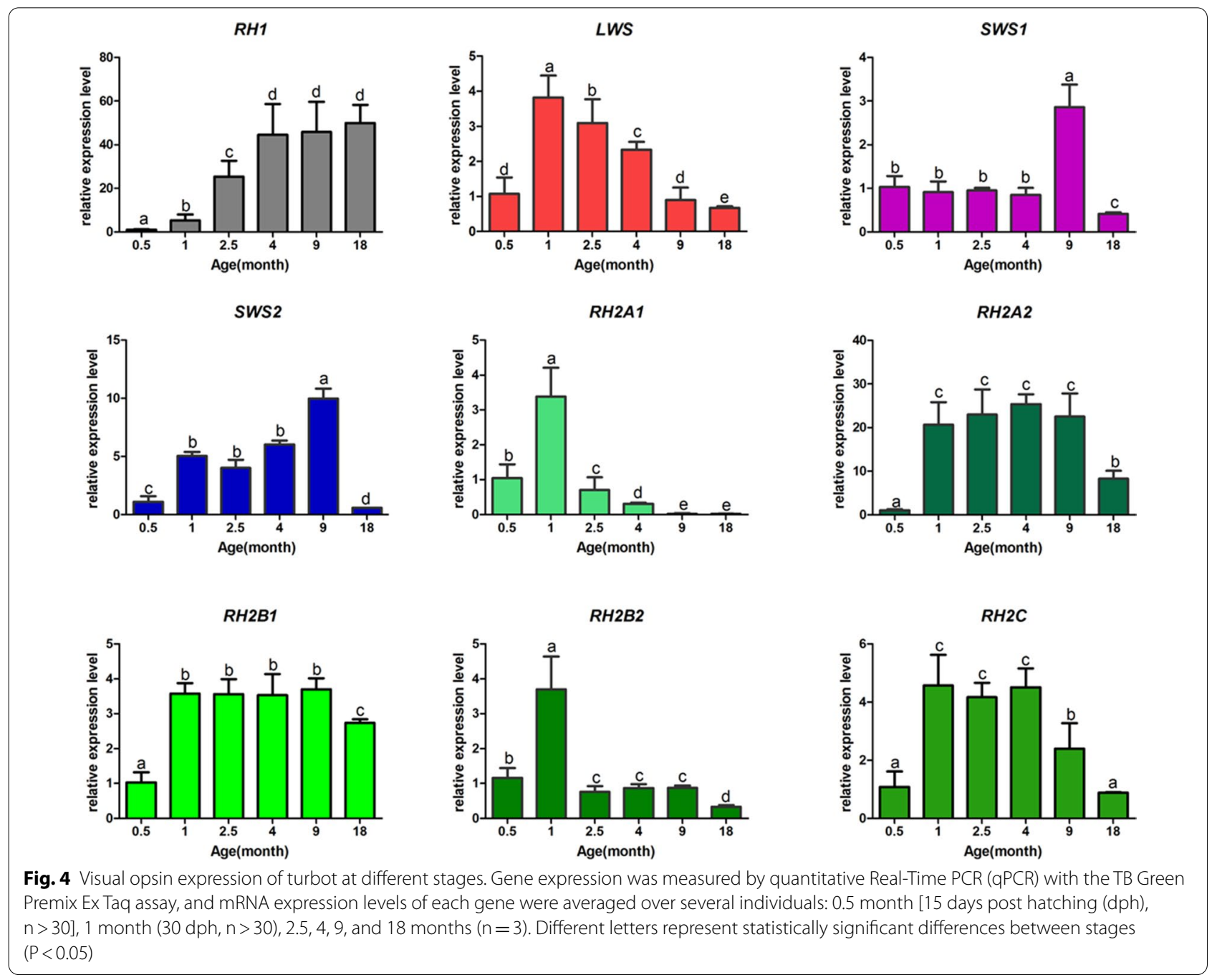


Table 5 Proportional expression of cone opsin genes of turbot at different stages

\begin{tabular}{lllll}
\hline Age (month) & LWS & RH2B1 & RH2C & Other \\
\hline 0.5 & $47.98^{\mathrm{a}}$ & $28.13^{\mathrm{a}}$ & $16.12^{\mathrm{a}}$ & $7.77^{\mathrm{a}}$ \\
1 & $53.85^{\mathrm{a}}$ & $26.14^{\mathrm{a}}$ & $13.29^{\mathrm{a}}$ & $6.71^{\mathrm{ab}}$ \\
2.5 & $47.43^{\mathrm{a}}$ & $34.13^{\mathrm{a}}$ & $14.51^{\mathrm{a}}$ & $3.93^{\mathrm{b}}$ \\
4 & $24.71^{\mathrm{b}}$ & $53.39^{\mathrm{b}}$ & $17.35^{\mathrm{a}}$ & $4.55^{\mathrm{b}}$ \\
9 & $14.64^{\mathrm{c}}$ & $63.27^{\mathrm{b}}$ & $18.74^{\mathrm{a}}$ & $3.35^{\mathrm{ab}}$ \\
18 & $29.22^{\mathrm{b}}$ & $57.19^{\mathrm{b}}$ & $11.22^{\mathrm{b}}$ & $2.37^{\mathrm{b}}$ \\
\hline
\end{tabular}

Different letters represent statistically significant differences between stages $(P<0.05)$

\section{Discussion}

\section{Molecular evolution of RH2 and RH1}

Through phylogenetic analysis, we characterized the visual opsin genetic component of turbot. Five green opsin genes are present in the turbot genome, and this is the same number as Pacific bluefin tuna (Thunnus orientalis) $[10,30]$. Our gene synteny analysis showed that $R H 2 C$ was not in the same gene cluster as the other four $\mathrm{RH} 2$ genes. In addition, the $R H 2 C$ locus was absent in other teleost species analyzed in this study. Unfortunately, our gene synteny analysis failed to cover all species of fish, including some flatfish such as barfin flounder, spotted halibut, and Japanese flounder, so we do not know yet whether their $R H 2 C$ s are arranged in tandem with other $\mathrm{RH} 2$ genes on the chromosome. Additionally, despite the close genetic relationship of tongue sole, it lacks the $\mathrm{RH} 2 \mathrm{C}$ locus. We predicted that $\mathrm{RH} 2 \mathrm{C}$ might have originated from flatfish-specific duplication, after which it was translocated to chromosome 8 from chromosome 6 in turbot. It is generally accepted that gene duplication may generate redundant genes, which is usually followed by degenerative mutations in one member of the pair and even gene loss [13, 31, 32]. Subsequently, some flatfish lineages lost $R H 2 C$, whereas other species such as turbot retained it.

We detected 10 positive selection sites of $\mathrm{RH} 2 \mathrm{C}$, and sites 122 and 207 are related to spectral sensitivity. In barfin flounder, the $\lambda_{\max }$ of RH2C is blue shifted by approximately $16 \mathrm{~nm}$ compared to RH2B [33]. Additionally, mutagenesis experiments in coelacanth indicated that both E122Q and M207L cause blue shifts of spectral peak absorbances $[3,34,35]$. Thus, we speculated that the $\lambda_{\max }$ of RH2A1, RH2A2, and $\mathrm{RH} 2 \mathrm{C}$ are blue shifted in turbot. Moreover, in turbot, multiple copies of RH2 encode green opsins with different $\lambda_{\max }$, as is found in zebrafish and medaka $[7,8]$. Different spectral peak absorbances are beneficial because they allow the fish to discriminate a wider spectrum of light. It may enhance color vision and contribute to prey detection in the bluish ocean [10]. Based on the loss of $R H 2 A$ function in the genus Verasper [11] and our results showing low expression levels of $R H 2 B 2$ and pairs of $R H 2 A$, we deduce that $R H 2 B 1$ and $R H 2 C$ are the higher expressed $R H 2$ genes in turbot. Furthermore, the retention of $R H 2 C$ is an adaptation of turbot to the spectral environment in the deep sea due to its shortwave-shift of $\lambda_{\max }$. Additionally, some studies have shown that opsin genes are tied to nuptial and body coloration [36, 37], but further work is required to confirm this function. Regarding the $R H 1$ genes, all flatfish species studied herein have the substitution of D83N, which has been demonstrated to cause blue shift in cattle and chameleons [38]. However, this site was not positively selected. Therefore, whether this replacement is beneficial for benthic adaptation needs further study. For the other three sites, no differences were found in nine fish species [39-41].

\section{Heterochronic changes in opsin gene expression}

Heterochronic changes in a variety of traits have been reported, including opsin gene expression [15, 42-45]. A study of cichlids revealed that subfunctionalization of heterochronic changes in expression patterns is critical for preservation of opsin genes [46]. Furthermore, altering opsin expression patterns during ontogeny is an important mechanism for modulating color vision [14]. In order to adapt to different life cycle stages, organisms show three patterns of heterochronic changes in opsin gene expression. For instance, in cichlid fishes, Nile tilapia showed a normal pattern of opsin gene expression that changes dynamically from a larval gene set to a final adult set. In contrast, cichlids from Lake Victoria had only an adult gene set with little change through time (direct developing pattern), and rock dwellers from Lake Malawi had a reduced rate of change (neotenic pattern) [15]. In the current study, we found a normal pattern of visual opsin expression in turbot. Turbot undergo metamorphosis during growth and development, which is accompanied by changes in the spectral environment: the bright daylight and long wavelength spectrum environment during the pelagic phase and the dim light and short to medium wavelength spectrum environment in the benthic phase. Transformation of light environments in turn might lead to shifts in opsin gene expression and spectral sensitivity [47]. Our results showed that turbot undergo heterochronic shifts in opsin gene expression, which may alter spectral sensitivity and contribute to scotopic vision. Specifically, the increased expression level of $R H 1$ is beneficial for vision in diminishing luminance when the fish moves to deeper waters. As for cone opsin genes, the highest proportional expression level of $L W S$ at the early developmental stages was gradually replaced by $R H 2 B 1$ at the later developmental stages 
during ontogeny. This variation means that the visual sensitivity shifts from red to green during adaptation to the deep sea environment. Downregulation of LWS and upregulation of RH1 expression level were also found during development in barfin flounder [33]. Similarly, no rod photoreceptors were found in retinas of larval winter flounder (Pseudopleuronectes americanus), indicating no expression of $R H 1$, whereas three types of photoreceptors with different $\lambda_{\max }$, including rods, were present in adult retinas. These results indicate increased $R H 1$ expression and a shift in spectral sensitivity [47]. In our study of turbot, we found low expression of cone opsins and a slight increase in proportional level of $L W S$ at 18 months of age. At that stage, turbot completed metamorphosis and moved to deeper waters. Thus, color vision seems not to be important for turbot in the deep sea, and higher LWS expression may occur in preparation for reproduction.

\section{Genetically based versus environmentally triggered variation}

The developmental progression in opsin expression is strongly linked to shifts in spectral sensitivity, which is generally considered to be an adaptation strategy to ambient light changes that occur over the life cycle [14, 15]. Studies on bluefin killifish (Lucania goodei) suggest lighting environment had large effects on opsin expression [20]. However, it is reported that opsin expression plasticity in cod larvae is controlled by developmental programme rather than ambient light [5]. It is not yet clear whether heterochronic shifts in opsin expression are genetically determined or environmentally triggered. Generally speaking, opsin expression should not need to change if there are no differences in the environmental spectrum. However, in the present study, we found that the turbot, which has been artificially domesticated for a long time, still showed variation of opsin expression in the same spectral environment during different developmental stages. Earlier studies suggest that photoperiod manipulation has an impact on performance, maturation and flesh quality in turbot $[48,49]$. And our lab had showed the plasticity of vision and body development of turbot larvae under different light spectra [29]. It is a pity that we have no turbot in natural environments to be compared with, whether the variation of opsin expression is triggered by environmental factors needs further study.

\section{The eye migration and evolutionary origin of flatfish asymmetry}

Darwin had noticed the eye asymmetry of flatfish, but the evolutionary origin was unclear, because there are no transitional forms linking flatfishes to symmetrical relatives. Thus, Darwin proposed a conjecture that invoked the inheritance of acquired traits like Lamarck's theory of flatfish origins, to respond to early arguments against natural selection. Until the discovery of the extinct spinyfinned fishes Amphistium and Heteronectes, which retain many primitive characters unknown in extant species. It indicates that the evolution of the eye asymmetry of flatfishes was gradual $[50,51]$. At present, it is generally accepted that flatfishes (Pleuronectiformes) are monophyletic groups [52, 53]. If it is true, important changes for adaptation to benthic lifestyle should be shared by Pleuronectiformes. Meanwhile, a fast adaptive radiation occurring $\sim 40$ Mya may play a great role in evolutionary history of each family or species [30]. Our results of divergence time of turbot $\mathrm{RH} 2$ genes help provide reference points.

\section{Conclusions}

Our results indicate that evolutionary changes in gene sequences and heterochronic shifts in opsin expression are the main ways that turbot adapt to environmental photic variations from the pelagic to the benthic period. Specifically, the positive selection of E122Q and M207L of $R H 2 C$ is closely related to a blue shift of the spectral peak absorbance, and $R H 2 C$ may be an important green opsin gene retained by some flatfish species, including turbot, after gene duplication. In addition, spectral sensitivities tuned by heterochronic shifts in opsin expression is another strategy to adapt to different ambient light spectra during the life cycle.

\section{Methods \\ Phylogenetic and synteny analysis}

To identify the visual opsin gene repertoire of turbot, zebrafish opsin sequences were used as BLASTp query sequences with e-value $<10^{-10}$, and they were downloaded from the chromosome of the reference genome [30]. Opsin sequences of four flatfish (spotted halibut, Verasper variegatus; Japanese flounder, Paralichthys olivaceus; barfin flounder, Verasper moseri, and Atlantic halibut, Hippoglossus hippoglossus) and four freshwater species living in shallow water (zebrafish, Danio rerio; medaka, Oryzias latipes; guppy; and zebra mbuna, Maylandia zebra) were obtained from GenBank (Additional file 2) [10, 11, 33, 54, 55]. Phylogenetic relationships among the visual opsin nucleotide sequences were inferred using MEGA 7 software [56] by applying the maximum-likelihood method [57] and Kimura twoparameter model algorithm [58]. The reliability of tree topology was evaluated by bootstrap analysis with 1000 replications and uniform rates among sites. Genomicus synteny [59] and Ensembl genome browsers were used to assess the syntenic regions between turbot and five other teleost genomes (tongue sole, Cynoglossus semilaevis; 
Japanese medaka HNI; zebra mbuna; zebrafish, and guppy).

\section{Branch and branch-site test of selection}

To estimate the differences in selection pressure between five benthic species and four shallow water pelagic species, branch-specific models and branch-site models of maximum likelihood were implemented in the CODEML program of PAML4.9i [60]. Tree topologies of each gene obtained by neighbor-joining method were provided in Additional file 1: Fig. S1. First, we compared the one-ratio model and free-ratios model in the branch test of selection [61], to test whether positive selection is present. It attempted to investigate if different spectral environments have an impact on the evolution of opsin genes. We then compared null Model A against the alternative Model A in the branch-site test to determine whether there are positively selected sites was present. This step was tried to explore the differences in selection pressure acted on not only branches but also sites of amino acids. Different sets of foreground lineages (the lineages selected for branch-site test) were marked with letters in each gene tree (Additional file 1: Fig. S1) [62]. The likelihood ratio test (LRT) was used to compare all alternative models and their corresponding null models. The Bayes Empirical Bayes method was used to obtain the posterior probability of sites under positive selection [63].

\section{Analysis of spectral tuning sites}

Representative spectral tuning sites of amino acids were compared among the opsins of five benthic and four shallow water pelagic species. The sites obtained by sitedirected mutagenesis were referenced from a previous study $[10,38]$. Amino acid sequence alignments were performed using ClustalX [64]. The number of amino acid sites was standardized to bovine rhodopsin, except for blue opsin, which was standardized to barfin flounder SWS2A.

\section{Estimation of turbot $R H 2$ divergence times}

The divergence time of turbot RH2 genes was estimated by MCMCTREE within PAML4.9i [60, 65]. The neighbor-joining tree of six species (turbot; Atlantic salmon, Salmo salar; fugu, Takifugu rubripes; common carp, Cyprinus carpio; lungfish, Neoceratodus forsteri, and rainbow trout) was acquired by MEGA 7 by neighbor-joining method. The fossil calibrations were adopted from TimeTree [66]. The tree topology and fossil calibrations were set as $(((((($ S.maximus_RH2B1, S.maximus_RH2B2), S.maximus_RH2C), T.rubripes_RH2), (S.maximus_ RH2A1, S.maximus_RH2A2)), (S.salar_RH2, O.mykiss_ RH2)) '>1.86<2.27', (C.carpio_RH2-1, C.carpio_RH2-2))
' $>2.05<2.55$ ', N.forsteri_RH2). The RootAge was set as ' $<6.0$ '.

\section{Quantification of turbot opsin RNA expression}

Laval and juvenile turbot were bred from a captive population at Shenghang Aquatic Science and Technology Company (Weihai, Shandong Province, China). The light period was 14L:10D and all individuals for mRNA expression analysis were euthanized with $300 \mathrm{mg} / \mathrm{L}$ of MS-222 (Sigma, Shanghai, China) between 9 and 12 am before being decapitated. The eyes were removed and immediately stored in liquid nitrogen until analyzed. Developmental stage was determined on the basis of the position of the rotating eye external characters [28]. Specifically, the ages of the individuals used for analysis of heterochronic shifts in opsin gene expression were: 0.5 month (15 days post hatch, larval stage), 1 month (metamorphic stage, the right eye has risen to the top of the head), 4 , 9 and 18 months (post-metamorphic stage, asymmetric, the body color has changed to silvery gray).

Total RNA was extracted using the RNA Isolation Kit (Vazyme Biotech Co, Nanjing, China). RNA purity and concentration were examined using a NanoDrop 2000 spectrophotometer (Thermo Scientific, Shanghai, China), and RNA integrity was verified by gel electrophoresis. The PrimeScript RT reagent kit with gDNA Eraser was used to synthesize first-strand cDNA from $0.5 \mu \mathrm{g}$ of total RNA (TaKaRa, Dalian, China). Using the Bio-Rad CFX Connect $^{\text {TM }}$ Real-Time PCR System (Bio-Rad, Hercules, CA, USA), quantitative real-time PCR (qPCR) was conducted with TB Green Premix Ex Taq (TaKaRa) following the manufacturer's protocol. Melting curves were plotted to confirm amplification specificity. Using the $2^{-\Delta \Delta C t}$ method, the relative expression level of each opsin gene was normalized to $\beta$-actin, which was selected as the internal reference gene after evaluating the expression pattern of eight commonly used housekeeping genes [67]. Additional file 1: Table S1 shows the specific primers for qPCR. The PCR mixture $(20 \mu \mathrm{L})$ contained $10 \mu \mathrm{L}$ of TB Green Premix Ex Taq, 7.6 $\mu \mathrm{L}$ of PCR-grade water, $1.6 \mu \mathrm{L}$ of cDNA, and $0.4 \mu \mathrm{L}$ of each of the primers. The qPCR reaction was performed in triplicate with the program of $95{ }^{\circ} \mathrm{C}$ for $3 \mathrm{~min}$, followed by 40 cycles at $95{ }^{\circ} \mathrm{C}$ for $10 \mathrm{~s}$, $57 / 58{ }^{\circ} \mathrm{C}$ for $30 \mathrm{~s}$, and $72{ }^{\circ} \mathrm{C}$ for $30 \mathrm{~s}$. Proportional opsin expression was determined as a fraction by calculating the proportion of each cone opsin $\left(T_{i}\right)$ relative to the total cone opsin expression $\left(T_{\text {all }}\right)$ as follows:

$$
\frac{T_{i}}{T_{\text {all }}}=\frac{\frac{1}{\left(1+E_{1}\right)^{C_{t i}}}}{\sum \frac{1}{\left(1+E_{i}\right)^{C_{t i}}}}
$$


where $E_{i}$ represents the PCR efficiency for each pair of primers and $C_{t i}$ is the critical cycle number for each gene $[68,69]$.

To assess significance of the change in opsin expression between different stages, the least significant difference (LSD) post hoc test with 95\% confidence level was used. Data were analyzed using SPSS 23.0 software. Relative expression data are shown as the mean \pm standard deviation, and proportional expression data are shown as averages.

\begin{abstract}
Abbreviations
RH1: Rhodopsin; RH2: Rhodopsin-like opsin; SWS1: Short wavelength-sensitive opsin 1; SWS2: SWS1-like opsin; LWS: Long wavelength-sensitive opsin; $\lambda_{\max }$ : Spectral peak absorbances; LRT: The likelihood ratio test; $\omega$ values: Nonsynonymous/synonymous rate ratio; N: Asparagine; D: Aspartic acid; E: Glutamic acid; Q: Glutamine; M: Methionine; L: Leucine; F: Phenylalanine; A: Alanine; S: Serine; V:Valine; T: Threonine; Mya: Million years ago; $q P C R$ : Quantitative real-time PCR; LSD: Least significant difference.
\end{abstract}

\section{Supplementary Information}

The online version contains supplementary material available at https://doi. org/10.1186/s12862-021-01837-2.

Additional file 1. Additional Figs. S1-7, Table S1-4.

Additional file 2. NCBI accession numbers used in this study.

\section{Acknowledgements}

We thank International Science Editing (http://www.internationalscienceediti ng.com) for editing this manuscript. Thanks to Dr. Hao Song for his comments on the article.

\section{Authors' contributions}

YW, XL, JL designed the study; LZ, LW, CS, XM, SX and TD participated in sampling. YW conducted all analysis; YW, XL and JL contributed to writing the paper. All authors read and approved the final manuscript.

\section{Funding}

This worked was supported by the National Natural Science Foundation (Grant no. 41976122, funded by National Natural Science Foundation of China), National Key R\&D Program of China (Grant no. 2017YFB0404000, funded by Ministry of Science and Technology of the People's Republic of China), Key R\&D Program of Shandong Province (Grant no. 2018GHY115031, funded by Department of Science and Technology of Shandong Province), Key R\&D Program of Guangdong Province (Grant no. 2019B020215001، funded by Department of Science and Technology of Guangdong Province) and China Agriculture Research System (CARS-47, funded by Ministry of Agriculture and Rural Affairs of the People's Republic of China).

\section{Availability of data and materials}

All NCBI accession numbers used in this study are listed in Additional file 2. The datasets used and analysed during the current study are available at Dryad: https://doi.org/10.5061/dryad.djh9w0w0m.

\section{Declarations}

\section{Ethics approval and consent to participate}

All experiments were performed in accordance with the relevant national and international guidelines and approved by the Institutional Animal Care and Use Committee, Institute of Oceanology, Chinese Academy of Sciences.
Consent for publication

Not applicable.

\section{Competing interests}

The authors declare that they have no competing interests.

\section{Author details}

${ }^{1}$ College of Fisheries, Ocean University of China, Qingdao 266003, People's Republic of China. ${ }^{2}$ CAS Key Laboratory of Experimental Marine Biology, Institute of Oceanology, Chinese Academy of Sciences, Qingdao 266071, People's Republic of China. ${ }^{3}$ Laboratory for Marine Biology and Biotechnology, Qingdao National Laboratory for Marine Science and Technology, Qingdao 266071, People's Republic of China. ${ }^{4}$ Center for Ocean Mega-Science, Chinese Academy of Sciences, Qingdao 266071, PR China. Institute of Semiconductors, Chinese Academy of Science, Beijing 100083, People's Republic of China.

Received: 23 March 2020 Accepted: 24 May 2021

Published online: 07 June 2021

\section{References}

1. Davies WI, Collin SP, Hunt DM. Molecular ecology and adaptation of visual photopigments in craniates. Mol Ecol. 2012;21:3121-58.

2. Hauser FE, Chang BSW. Insights into visual pigment adaptation and diversity from model ecological and evolutionary systems. Curr Opin Genet Dev. 2017:47:110-20.

3. Yokoyama S. Molecular evolution of color vision in vertebrates. Gene. 2002;300:69-78.

4. Endler JA. Signals, signal conditions, and the direction of evolution. Am Nat. 1992:139:5125-53.

5. Valen R, Karlsen R, Helvik JV. Environmental, population and life-stage plasticity in the visual system of Atlantic cod. J Exp Biol. 2018;221:UNSP j165191.

6. Nordstrom K, Larsson TA, Larhammar D. Extensive duplications of phototransduction genes in early vertebrate evolution correlate with block (chromosome) duplications. Genomics. 2004;83:852-72.

7. Chinen A, Hamaoka T, Yamada Y, Kawamura S. Gene duplication and spectral diversification of cone visual pigments of zebrafish. Genetics. 2003;163:663-75.

8. Matsumoto Y, Fukamachi S, Mitani H, Kawamura S. Functional characterization of visual opsin repertoire in Medaka (Oryzias latipes). Gene. 2006;371:268-78

9. Watson CT, Gray SM, Hoffmann M, Lubieniecki KP, Joy JB, Sandkam BA, et al. Gene duplication and divergence of long wavelength-sensitive opsin genes in the guppy, Poecilia reticulata. J Mol Evol. 2011;72:240-52.

10. Nakamura Y, Mori K, Saitoh K, Oshima K, Mekuchi M, Sugaya T, et al. Evolutionary changes of multiple visual pigment genes in the complete genome of Pacific bluefin tuna. PNAS. 2013;110:11061-6.

11. Kasagi S, Mizusawa K, Takahashi A. Green-shifting of SWS2A opsin sensitivity and loss of function of $\mathrm{RH} 2-\mathrm{A}$ opsin in flounders, genus Verasper. Ecol Evol. 2018;8:1399-410.

12. Liu DW, Wang FY, Lin JJ, Thompson A, Lu Y, Vo D, et al. The cone opsin repertoire of osteoglossomorph fishes: gene loss in mormyrid electric fish and a long wavelength-sensitive cone opsin that survived 3R. Mol Biol Evol. 2019;36:447-57.

13. Rennison DJ, Owens GL, Taylor JS. Opsin gene duplication and divergence in ray-finned fish. Mol Phylogenet Evol. 2012;62:986-1008.

14. Cheng $\mathrm{CL}$, Flamarique IN. New mechanism for modulating colour vision. Nature. 2004;428:279.

15. Carleton KL, Spady TC, Streelman JT, Kidd MR, McFarland WN, Loew ER. Visual sensitivities tuned by heterochronic shifts in opsin gene expression. Bmc Biol. 2008;6:22.

16. Cheng CL, Flamarique IN. Chromatic organization of cone photoreceptors in the retina of rainbow trout: single cones irreversibly switch from UV (SWS1) to blue (SWS2) light sensitive opsin during natural development. J Exp Biol. 2007;10:4123-35.

17. Mader MM, Cameron DA. Photoreceptor differentiation during retinal development, growth, and regeneration in a metamorphic vertebrate. J Neurosci. 2004;24:11463-72. 
18. Hornsby MAW, Sabbah S, Robertson RM, Hawryshyn CW. Modulation of environmental light alters reception and production of visual signals in Nile tilapia. J Exp Biol. 2013;216:3110-22.

19. EhIman SM, Sandkam BA, Breden F, Sih A. Developmental plasticity in vision and behavior may help guppies overcome increased turbidity. J Comp Physiol A. 2015;201:1125-35.

20. Fuller RC, Claricoates KM. Rapid light-induced shifts in opsin expression: finding new opsins, discerning mechanisms of change, and implications for visual sensitivity. Mol Ecol. 2011;20:3321-35.

21. Chang $\mathrm{CH}$, Yan HY. Plasticity of opsin gene expression in the adult red shiner (Cyprinella lutrensis) in response to turbid habitats. PLOS ONE. 2019;14:0215376.

22. Dalton BE, Loew ER, Cronin TW, Carleton KL. Spectral tuning by opsin coexpression in retinal regions that view different parts of the visual field. P Roy Soc B-Biol Sci. 2014;281:20141980.

23. Harer A, Karagic N, Meyer A, Torres-Dowdall J. Reverting ontogeny: rapid phenotypic plasticity of colour vision in cichlid fish. Royal Society Open Sci. 2019;6:190841.

24. Thorisson K. Is metamorphosis a critical interval in the early life of marine fishes? Environ Biol Fishes. 1994:40:23-36.

25. Gwak W, Tanaka M. Changes in RNA, DNA and protein contents of laboratory-reared Japanese flounder Paralichthys olivaceus during metamorphosis and settlement. Fish Sci. 2010;68:27-33.

26. Al-Maghazachi SJ, Gibson R. The developmental stages of larval turbot, Scophthalmus maximus (L.). J Exp Marine Biol Ecol. 1984;82:35-51.

27. Tong XH, Liu QH, Xu SH, Li J, Xiao ZZ, Ma DY. Changes in RNA, DNA, protein contents and growth of turbot Scophthalmus maximus larvae and juveniles. J Fish Biol. 2010;77:512-25.

28. Encárnación DMV, María JDD, Castillo PA, Ramón AA. Development of the eye in the turbot Psetta maxima (Teleosti) from hatching through metamorphosis. J Morphol. 1997;233:31-42.

29. Han MM, Li X, Wu LL, Xu SH, Wang YF, Li J. The plasticity of vision and body development of turbot Scophthalmus maximus larvae Under different light spectra. Aquac Res. 2020;51:1-11.

30. Figueras A, Robledo D, Corvelo A, Hermida M, Pereiro P, Rubiolo JA, et al. Whole genome sequencing of turbot (Scophthalmus maximus; Pleuronectiformes): a fish adapted to demersal life. DNA Res, 2016:23:181-92

31. Force A, Lynch M, Pickett FB, Amores A, Yan HY, Postlethwait J. Preservation of duplicate genes by complementary, degenerative mutations. Genetics. 1999;151:1531-45.

32. Lynch M, Force A. The probability of duplicate gene preservation by subfunctionalization. Genetics. 2000;154:459-73.

33. Kasagi S, Mizusawa K, Murakami N, Andoh T, Furufuji S, Kawamura S, et al. Molecular and functional characterization of opsins in barfin flounder (Verasper moseri). Gene. 2015:556:182-91.

34. Yokoyama S, Zhang H, Radlwimmer F, Blow N. Adaptive evolution of color vision of the Comoran coelacanth (Latimeria chalumnae). PNAS. 1999;96:6279-84

35. Yokoyama S, Tada T. Adaptive evolution of the African and Indonesian coelacanths to deep-sea environments. Gene. 2000;261:35-42.

36. Wang FY, Chung WS, Yan HY, Tzeng CS. Adaptive evolution of cone opsin genes in two colorful cyprinids, Opsariichthys pachycephalus and Candidia barbatus. Vision Res. 2008;48:1695-704.

37. Montenegro J, Mochida K, Matsui K, Mokodongan DF, Sumarto BKA, Lawelle SA, et al. Convergent evolution of body color between sympatric freshwater fishes via different visual sensory evolution. Ecol Evol. 2019:9:6389-98.

38. Yokoyama S. Molecular evolution of vertebrate visual pigments. Prog Retin Eye Res. 2000;19:385-419.

39. Hope AJ, Partridge JC, Dulai KS, Hunt DM. Mechanisms of wavelength tuning in the rod opsins of deep-sea fishes. P Roy Soc B-Biol Sci. 1997;264:155-63.

40. Yokoyama S, Takenaka N. The molecular basis of adaptive evolution of squirrelfish rhodopsins. Mol Biol Evol. 2004;21:2071-8.

41. Yokoyama S, Tada T, Zhang H, Britt L. Elucidation of phenotypic adaptations: molecular analyses of dim-light vision proteins in vertebrates. PNAS. 2006:105:13480-5.

42. Hanken J, Hall BK. Variation and timing of the cranial ossification sequence of the oriental fire-bellied toad, Bombina orientalis (Amphibia, Discoglossidae). J Morphol. 1984;182:245-55.
43. Schmidt A, Roth G. Differentiation processes in the amphibian brain with special emphasis on heterochronies. Int Rev Cytol. 1996;169:83-150.

44. Mabee PM, Olmstead KL, Cubbage CC. An experimental study of intraspecific variation, developmental timing, and heterochrony in fishes. Evolution. 2000;54:2091.

45. Linksvayer TA, Wade MJ. The evolutionary origin and elaboration of sociality in the aculeate hymenoptera: maternal effects, sib-social effects, and heterochrony. Q Rev Biol. 2005;80:317-36.

46. Spady TC, Parry JWL, Robinson PR, Hunt DM, Bowmaker JK, Carleton KL. Evolution of the cichlid visual palette through ontogenetic subfunctionalization of the opsin gene arrays. Mol Biol Evol. 2006;23:1538-47.

47. Evans BI, Harosi FI, Fernald RD. Photoreceptor spectral absorbance in larval and adult winter flounder (Pseudopleuronectes americanus). Visual Neurosci. 1993;10:1065-71.

48. Albert Kl, Snorri G, Bjørn R, Atle F, Soizic LD, Birgitta N, et al. Long-term effect of photoperiod manipulation on growth, maturation and flesh quality in turbot. Aquaculture. 2013;152-160

49. Sierra-Flores R, Davie A, Grant B, Carboniet S, Atack T, Migaud H. Effects of light spectrum and tank background colour on Atlantic cod (Gadus morhua) and turbot (Scophthalmus maximus) larvae performances. Aquaculture. 2016;450:6-13.

50. Darwin C. On the origin of species by means of natural selection. Am Anthropol. 1963;61(1):176-7.

51. Friedman M. The evolutionary origin of flatfish asymmetry. Nature. 2008;454:209.

52. Chapleau F. Pleuronectiform relationships: a cladistic reassessment. B MAR SCI. 1993;52:516-40.

53. Berendzen PB, Dimmick WW. Phylogenetic relationships of Pleuronectiformes based on molecular evidence. Copeia. 2002;3:642-52.

54. Helvik JV, Drivenes O, Naess TH, Fjose A, Seo HC. Molecular cloning and characterization of five opsin genes from the marine flatfish Atlantic halibut (Hippoglossus hippoglossus). Vis Neurosci. 2001;18:767-80.

55. Laver CRJ, Taylor JS. RT-qPCR reveals opsin gene upregulation associated with age and sex in guppies (Poecilia reticulata): a species with color-based sexual selection and 11 visual-opsin genes. BMC Evol Biol. 2011;11:81.

56. Kumar S, Stecher G, Tamura K. MEGA7: molecular evolutionary genetics analysis version 7.0 for bigger datasets. Mol Biol Evol. 2016;3:1870-4.

57. Saitou N, Nei M. The neighbor-joining method: a new method for reconstructing phylogenetic trees. Mol Biol Evol. 1987;4:406-25.

58. Tateno $Y$, Takezaki $N$, Nei M. Relative efficiencies of the maximumlikelihood, neighbor-joining, and maximum-parsimony methods when substitution rate varies with site. Mol Biol Evol. 1994;2:261-77.

59. Nguyen NTT, Vincens P, Crollius HA, Louis A. Genomicus 2018: karyotype evolutionary trees and on-the-fly synteny computing. Nucleic Acids Res. 2018;46:816-22

60. Yang ZH. PAML 4: phylogenetic analysis by maximum likelihood. Mol Biol Evol. 2007:24:1586-91.

61. Yang ZH. Likelihood ratio tests for detecting positive selection and application to primate lysozyme evolution. Mol Biol Evol. 1998;15:568-73.

62. Zhang JZ, Nielsen R, Yang ZH. Evaluation of an improved branch-site likelihood method for detecting positive selection at the molecular level. Mol Biol Evol. 2005;22:2472-9.

63. Yang ZH, Wong WSH, Nielsen R. Bayes empirical bayes inference of amino acid sites under positive selection. Mol Biol Evol. 2005;22:1107-18.

64. Larkin MA, Blackshields G, Brown NP, Chenna R, McGettigan PA, McWilliam H, et al. Clustal W and Clustal X version 2.0. Bioinformatics. 2007;23:2947-8.

65. Yang ZH, Rannala B. Bayesian estimation of species divergence times under a molecular clock using multiple fossil calibrations with soft bounds. Mol Biol Evol. 2006;23(1):212-26.

66. Kumar S, Stecher G, Suleski M, Hedges SB. TimeTree: a resource for timelines, timetrees, and divergence times. Mol Biol Evol. 2017:34:1812-9.

67. Dang W, Sun L. Determination of internal controls for quantitative real time RT-PCR analysis of the effect of Edwardsiella tarda infection on gene expression in turbot (Scophthalmus maximus). Fish Shellfish Immun. 2011;30:720-8. 
68. Fuller RC, Carleton KL, Fadool JM, Spady TC, Travis J. Population variation in opsin expression in the bluefin killifish, Lucania goodei: a realtime PCR study. J Comp Physiol A. 2004;190:147-54.

69. Harer A, Torres-Dowdall J, Meyer A. Rapid adaptation to a novel light environment: The importance of ontogeny and phenotypic plasticity in shaping the visual system of Nicaraguan Midas cichlid fish (Amphilophus citrinellus spp.). Mol Ecol. 2017;26:5582-93.

\section{Publisher's Note}

Springer Nature remains neutral with regard to jurisdictional claims in published maps and institutional affiliations.
Ready to submit your research? Choose BMC and benefit from:

- fast, convenient online submission

- thorough peer review by experienced researchers in your field

- rapid publication on acceptance

- support for research data, including large and complex data types

- gold Open Access which fosters wider collaboration and increased citations

- maximum visibility for your research: over 100M website views per year

At BMC, research is always in progress.

Learn more biomedcentral.com/submissions 